\title{
Penciptaan Cinderamata \\ Ikon-Ikon Wisata Sejarah Sebagai Upaya Revitalisasi Budaya Lokal Kabupaten Sumedang
}

\author{
Ai Juju Rohaeni, Wanda Listiani, dan Khairul Mustaqin \\ Insitut Seni Budaya Indonesia (ISBI) Bandung \\ Jl. Buahbatu No. 212 Bandung 40265
}

Volume 5 Nomor 2,

Oktober 2018: 102-107

\begin{abstract}
ABSTRAK
Tempat wisata dan tokoh sejarah Kabupaten Sumedang menjadi sumber inspirasi pembuatan produk cinderamata. Cinderamata memiliki tiga syarat yaitu sebagai objek, kenangan dan hadiah. Objek memiliki nilai didalamnya atau simbol dari pengalaman seseorang di satu tempat/wilayah. Penelitian penciptaan dan penyajian seni ini menggunakan metode kualitatif dengan tahapan penciptaan eksplorasi, eksperimen dan finalisasi produk. Hasil penelitian penciptaan dan penyajian seni ini menjelaskan proses penciptaan cinderamata ikon Sumedang yaitu Menara Loji Jatinangor, Monumen Lingga, Pangeran Aria Soeria Atmadja dan benda-benda pusaka yang menjadi koleksi Museum Geusan Ulun yaitu Mahkota Binokasih yang pernah dipakai oleh Prabu Geusan Ulun, dan wisata kuliner yang sudah terkenal yaitu Tahu Sumedang. Sumber penciptaan yang dipilih berupa tempat, benda dan makanan khas Sumedang dikarenakan benda-benda tersebut memperlihatkan kekhasan Kabupaten Sumedang membedakan dengan peninggalan sejarah di daerah lain.
\end{abstract}

Kata kunci: revitalisasi; cinderamata; ikon wisata sejarah; kabupaten Sumedang

\begin{abstract}
Creation of Souvenirs Historical Icons as a Local Cultural Revitalization Efforts of Sumedang District. Tourist attractions and historical figures of Sumedang Regency become a source of inspiration for making souvenir products. Souvenirs have three conditions, namely as objects, memories and gifts. The object has a value in it or a symbol of someone's experience in one place / region. This research on the creation and presentation of art uses qualitative methods with the stages of creating exploration, experimentation and product finalization. The results of the research on the creation and presentation of the art explained the process of creating Sumedang iconic souvenirs, namely Jatinangor Loji Tower, Lingga Monument, Prince Aria Soeria Atmadja and heirlooms which were collections of the Geusan Ulun Museum, Mabkota Binokasih which was used by Prabu Geusan Ulun, and culinary tourism which is well known, namely Tahu Sumedang. The source of creation chosen is in the form of places, objects and special food of Sumedang because these objects show the distinctiveness of Sumedang District to distinguish it from historical relics in other regions.
\end{abstract}

Keywords: revitalization; souvenirs; historical tourism icon; Sumedang district

\section{Pendahuluan}

Setiap daerah memiliki potensi kerajinan dan karya seni berdasarkan sumber daya alam dan sumber daya manusia daerah tersebut. Sumedang sebagai salah satu kota puseur budaya pasundan yang kaya dengan beragam potensi tersebar di wilayah Kabupaten Sumedang memiliki 19 tempat/bangunan-bangunan bersejarah dan 11 berupa benda-benda pusaka sejarah yang menjadi koleksi Museum Geusan Ulun, situs dan artefak serta upacara-upacara Adat dan seni pertunjukan seperti; Ketuk Tilu, Bangreng, Wayang Golek, Silat, Gembyung, Kuda Renggong, Calung, Reog, Tari Wayang Gaya Kasumedangan dan lainlain. Tradisi-tradisi yang dilakukan dalam hidup 
bermasyarakat di kabupaten Sumedang hingga saat ini seperti adat istiadat, upacara-upacara yang melingkupi kehidupan masyarakatnya berkaitan dengan kepercayaan, alam, lingkaran hidup manusia, maupun dalam bentuk seni pertunjukan.

Potensi yang tersebar di desa dan kota Kabupaten terutama yang berkaitan dengan perjalanan sejarah Sumedang yang menjadi ikonikon Kota Sumedang baru bisa dikunjungi bagi wisatawan lokal maupun luar yang ingin melihat, terlihat pada Pameran. Kerajinan yang dipajang oleh komunitas pada anjungan pameran dari setiap kecamatan belum ada kerajinan mengangkat dari 19 tempat dan benda sejarah tersebut. Dengan membuat cinderamata inspirasi ikon-ikon Sumedang dapat menambah kekayaan kerajinan juga memberikan kesempatan pada pengrajin untuk membantu ekonomi masyarakatnya, serta sebagai upaya promosi daerah dengan dibuatkan bentuk-bentuk cinderamata yang dapat dipake, dihadiahkan, disimpan sebagai koleksi untuk dijadikan kenang-kenang sebagai tanda mata. Hal ini dapat dilihat pada saat Festival Kerajinan Produk Unggulan yang diselenggarakan pemerintah Kabupaten Sumedang pada Tanggal 27 sampai dengan 30 April tahun 2018 sebagai rangkaian acara Ulang Tahun hari jadi Kabupaten Sumedang ke 440 tanggal 22 April, yang bertempat di sepanjang jalan Raya Alun-alun Sumedang dan Pacuan Kuda.

Penyelenggaraan berbagai festival kesenian dan kebudayaan serta potensi lokal yang ada sebagai motivasi tim peneliti untuk menciptakan produk kerajinan. Fungsi kerajinan atau seni kriya adalah hiasan (dekorasi), pajangan yang lebih mengutamakan keindahan, bentuk sederhana dan bahan yang mudah didapatkan. Ada berbagai jenis seni kriya berdasarkan bahan yang digunakan yaitu kayu, teksil, keramik, logam, kulit, dan batu. Sedangkan jenis seni kriya berdasarkan teknik pembuatannya adalah seni pahat atau ukir, batik, tenun, anyaman dan border. Definisi produksi (Karthadinata, t.t: 194) adalah suatu kegiatan untuk meningkatkan nilai dan kegunaan barang. Produksi berkaitan dengan cara bagaimana mengerjakan atau mengolah suatu bahan sehingga menjadi barang jadi yang mempunyai nilai lebih (proses produksi), bahan dan peralatan yang digunakan serta faktorfaktor yang mempengaruhinya. Penelitian tentang seni kerajinan dilakukan oleh Mahroni dkk yaitu penelitian seni kerajinan di NTB dengan metode deskriptif analisis. Hasil penelitian menunjukkan bahwa seni kerajinan telah berkembang sehingga mampu memperlihatkan hasil serta pendapatan masyarakat NTB (Mahroni, 2014 : 76). Hasil penelitian Stewart Dick (Dick, 1912: 6) menjelaskan bahwa pengetahuan tentang sistem sosial masyarakat akan memberikan pemahaman yang lebih baik akan seni yang dihasilkan dan kualitas pengrajin

Penelitian penciptaan dan penyajian seni ini menggunakan metode kualitatif dengan tahapan penciptaan sebagai berikut:

1. Eksplorasi, dalam tahapan ini dilakukan pengkajian sumber ide, sketsa, mendiskripsikan masalah. Ikon khas Sumedang dibuat dalam bentuk image dan ditafsirkan oleh tim pengusul dalam berbagai bentuk metaphor baru dalam gambar sketsa. Kontemplasi mendalam pada bentuk "Ikon Khas Sumedang" yang telah dipilih memberikan pencitraan dan inspirasi dalam penciptaan. Dari obyek wisata sejarah baik berapa bangunan dan benda pusaka yang terdapat Di Kabupaten Sumedang dipilih beberapa yang khas dan tidak terdapat di daerah lain di luar Kabupaten Sumedang untuk dasar desain cinderamata khas.

2. Perencanaan dan eksperimen, dalam tahapan ini membuat predesain, desain dan membuat model sebagai awal dan pembuatan karya seni. Pertimbangan kebaruan (novelty) baik aspek teknis dan non teknis dilakukan untuk mencari berbagai kemungkinan pilihan desain dan pengolahan material kerajinan perhiasan yang dimiliki oleh kabupaten Sumedang. Dokumentasi setiap tahapan proses dan teknik pengerjaan dibuat sebagai bahan evaluasi dan penjelasan proses dalam berkarya. Sketsa sebagai visualisasi dari ide dan rancangan kerajinan perhiasan dari ikon khas Sumedang yang sudah dipilih.

3. Perwujudan, dalam tahapan ini dilakukan finalisasi karya seni, konstruksi dan pengujian artistik dan pemetaan produk sebelum karya disosialisasikan pada masyarakat. Visualisasi 
karya dibuat dalam bentuk dua dimensi dan tiga dimensi. Kesatuan komposisi rupa dan aplikasi bahan disesuaikan dengan karakter produk yang diinginkan. Muatan estetis, elegan dan detail rancangan merujuk pada proses perwujuduan ide hingga terciptanya produk. Wujud atau form bersifat representative dimana makna, pesan dan nilai serta shape secara cermat dipersiapkan dari awal. Kesatuan rupa ikon dan elemen simbol khas Sumedang disusun scara harmonis dan organis dalam bentuk kerajinan perhiasan. Pelapisan material dilakukan pada proses akhir untuk mendapatkan kesempurnaan dari produk kerajinan perhiasan ikon khas Sumedang.

Menurut Gustami (Mujiyono, 2010: 75) bahwa keunggulan karya seni rupa Indonesia masih sering diperdebatkan karenanya kurang dukungan data ilmiah; ekplorasi, mengkaji dan merumuskan ide dasar penciptaan dan metodologi proses kreatif seniman. Untuk itu dalam penelitian dasar unggulan perguruan tinggi ini tim pengusul mengumpulkan sebanyak mungkin data di lapangan khususnya ikon khas dan keragaman hayati kabupaten Sumedang dengan teknik pengumpulan data dokumentasi, pengamatan dan wawancara kepada masyarakat di kabupaten Sumedang.

\section{Pembahasan}

Tempat wisata dan tokoh sejarah Kabupaten Sumedang menjadi sumber inspirasi pembuatan produk cinderamata. Cinderamata memiliki tiga syarat yaitu sebagai objek, memorabilia (kenangan) dan sebagai hadiah. Objek memiliki nilai didalamnya atau simbol dari pengalaman seseorang di satu tempat/wilayah. Sebagai objek, mengasosiasikan dengan lokasi atau informasi geografis dimana cinderamata itu dibuat. Cinderamata sebagai obyek dapat diproduksi secara massal dan terbatas (customize). Cinderamata sebagai obyek merepresentasikan tradisi atau budaya tertentu, obyek alam seperti gunung, pantai, hutan dan sebagainya yang memiliki nilai kenangan dan bisa dikoleksi atau dimiliki oleh seseorang. Ada berbagai pilihan ikon Sumedang yaitu Menara Loji Jatinangor, Monumen Lingga, dan benda-benda pusaka yang menjadi koleksi Museum Geusan Ulun yaitu Mahkota Binokasih yang pernah dipakai oleh Prabu Geusan Ulun, dan wisata kuliner yang sudah terkenal yaitu Tahu Sumedang serta tokoh seorang Pangeran yang merupakan cikal bakal Sumedang menjadi kabupaten.

Sumber penciptaan yang dipilih berupa tempat, benda dan makanan khas Sumedang dikarenakan benda-benda tersebut memperlihatkan kekhasan Kabupaten Sumedang membedakan dengan peninggalan sejarah di daerah lain. Berikut desain cinderamata khas Sumedang:

1. Monumen Lingga Sumedang

Monumen Lingga di tengah alun-alun Sumedang merupakan monumen penghormatan kepada Pangeran Aria Suria Atmadja. Monumen yang diresmikan Gubernur Jenderal D. Fock, bupati, residen, dan pejabat Belanda. Beberapa tanda jasa dari pemerintah Belanda yaitu Groot Gouden Ster (1891) dan anugerah bintang jasa tahun 1901, 1903, 1918, Payung Song-song Kuning tahun 1905, Gelar Adipati 1898, Gelar Aria 1906 dan Gelar Pangeran 1910 (Lasmiyati, 2014: 236). Jasa bupati Sumedang di berbagai bidang antara lain (Lasmiyati, 2014: 228):

a. Bidang Peternakan, mendatangkan sapi dari Madura dan Benggala, kuda dari Sumba atau Sumbawa.

b. Bidang Kehutanan, penanaman pohon agar gunung yang gundul tidak longsor dan pembuatan hutan larangan/hutan tertutup.

c. Bidang Komunikasi, membangun kantor telepon.

d. Bidang Perbankan, membangun Bank Prijaji pada tahun 1901 dan tahun 1910 diubah menjadi Soemedangsche Afdeeling Bank.

e. Bidang Kesenian, memajukan Tari Tayub dan Degung, membuat buku "Ditioeng Memeh Hoedjan" dan menciptakan lagu "Sonteng".

f. Bidang Pertanian, membangun irigasi, lumbung desa dan pembuatan sistem tangga (terasering) .

g. Bidang Pendidikan, mendirikan sekolah tani sebagai cikal bakal Akademi Pertanian Tanjungsari yang berkembang menjadi Universitas Winayamukti (Unwim), mem- 
bangun Hollandsch Inlandsche School.

h. Bidang Keamanan, dibangun pos keamanan/penjaga ronda.

Monumen Lingga Sumedang dindingnya terdapat tulisan, "Kita sekalian bersama sama umatnja Tuhan lagi seasal dan seturunan kalau dipimpin oleh jang paling sempurna jang berhati sutji dan bidjaksana aman dan tenteram keadaan negara". Ikon wisata sejarah Monumen lingga juga dapat digunakan sebagai inspirasi cinderamata liontin kalung sekaligus flashdisk dengan teknik grafir.

2. Menara Loji Jatinangor

Menara Loji berdiri sejak tahun 1800an yang berdiri di kawasan perkebunan karet milik orang Jerman.

3. Tahu Sumedang

Kata tahu berasal dari Tionghoa yang berarti tao/teu (kacang kedelai) dan hu berarti hancur. Tahu disajikan orang Tionghoa sejak abad ke-10 (www.historia.id). Tahu sebagai sumber pangan alternatif pada masa cultuurstelsel (tanam paksa). Tahu menjadi ikon khas daerah Sumedang. Imigran Tionghoa bernama Ong Kino membuat tahu di Tegal Kalong Sumedang pada masa Pangeran Situraja (www. goodnewsfromindonesia.id).

Tempat Kuliner Tahu Sumedang di Sepanjang Jalan dari Jalan Prabu Gajah Agung sampai Bunderan Alam Sari menuju arah Bandung-Cirebon. Rumah makan tahu seperti RM. Bungkeng, RM. Yoefo, RM. Ojolali, RM. Palasari, RM. Mirasa, RM. Citarasa, RM. H. Ateng, RM. Saribumi Tahu, RM. Sindang Sari, RM. Citasari dan sebagainya.

Kuliner Tahu Sumedang yang mempunyai ciri dengan keranjang bambu yang dianyam, selama ini hanya dinikmati di tempat juga dibawa sebagai oleh-oleh untuk dimakan saja, menjadi inspirasi untuk dapat menjadi berbagai bentuk cinderamata dari berbagai bahan, tehnik, bentuk dan fungsi agar menjadi buah tangan yang bertahan lama yang bisa dilihat, dipakai sebagai asesoris yang menarik terutama yang bisa dipakai oleh kalangan remaja sebagai pelengkap dalam berbusana sehingga penapilannya lebih menarik Selain itu dengan dibuat berbagai jenis pernak-pernik dapat menjadi buah tangan yang berharga dan tahan lama.

Pembuatan cinderamata dengan mengangkat tahu Sumedang kuliner khas, mempunyai fungsi sebagai makanan cemilan yang dipadukan bisa dengan lontong tetapi juga masyarakat Sumedang Tahu sebagai lauknya makan nasi. Pembuatan Tahu dengan berbagai produk Cinderamata memberi peluang pada masyarakat untuk kreatif dan inovatif yang akan berpengaruh pada peluang lapangan kerja dan untuk meningkatkan juga promosi daerah Sumedang yang kaya akan tempat wisata. Keberadaan lokasi wisata yang tersebar didesa-desa di wilayah Sumedang, memberi peluang dan kesempatan pada pemerintah dan masyarakatnya untuk memperkenalkan salah satunya tahu dengan menyediakan tempat pameran ikon-ikon khas sendiri.

Setiap daerah atau kota terdapat produk tahu, namun yang menjadikan tahu Sumedang berbeda adalah bahan baku kedelai sebagai bahan dasar pembuatan tahu tidak menggunakan kedelai inpor tetapi kedelai lokal daerah. Kemudian air yang bersumber dari mata air Sumedang sangat berpengaruh terhadap cita rasa tahu. Proses pengolahan tahu tidak tercampur dengan ampas kedelainya. Serta tidak memakai bumbu lain untuk menambah rasa tetapi murni dari pemilihan kedelai yang dipergunakan, sehingga tahu Sumedang setelah dimasak/ digoreng bentuk dan rasanya khas, sangat berbeda dengan tahu-tahu dari daerah lain.

Bentuk tahu Sumedang menjadi inspirasi untuk membuat miniatur tahu, cabai rawit dan ubi Cilembu yang dapat dijadikan cinderramata (miniatur makanan khas Sumedang), perhiasan (cincin, bandul kalung, anting-anting) dan gantungan kunci. Miniatur Tahu Sumedang berbahan Air dry Clay menjadi berbagai bandul kalung atau liontin. Selain eksplorasi material Clay, digunakan juga material logam seperti perak untuk bandul atau kalung berbentuk Tahu Sumedang.

4. Mahkota Binokasih

Binokasih Sanghyang Pake merupakan mahkota dari kerajaan Sunda yang menjadi 
koleksi Museum Prabu Geusan Ulun Sumedang. Mahkota ini dibuat oleh Sanghyang Bunisora Suradipati, Raja Galuh tahun 1357-1371. Mahkota Binokasih digunakan oleh raja-raja Sunda dalam upacara pelantikan raja baru termasuk pernah dipakai oleh Prabu Geusan Ulun (https:/id.wikipedia.org). Motif Mahkota Binokasih menjadi inspirasi sebagai hiasan jilbab dan cincin berbahan logam perak.

5. Pangeran Aria Soeria Atmadja

Pangeran Suria Atmaja lahir pada 11 Januari 1851 dengan nama Pangeran Sadeli, pernah menjadi patih afdeling Sukapura Kolot di Mangunreja. Pangeran Suria Atmaja dilantik sebagai bupati sumedang tanggal 31 Januari 1883 dengan gelar Aria. Pangeran Aria Suria Atmaja merupakan bupati terakhir dan mendapat sebutan Pangeran Panungtung dan Pangeran Mekah (Lasmiyati, 2014: 227). Foto Pangeran Aria Soeria Atmadja diproses dalam berbagai tampilan dengan menggunakan software photoshop untuk mendapatkan desain foto sesuai konsep cinderamata kaos. Quotation Pangeran Aria Soeria Atmadja yang terkenal dan berbagai tulisannya tentang perlawanan, perjuangan menghadapi Belanda dapat menjadi tambahan teks dalam desain produk kaos cinderamata ikon Sumedang.

\section{Simpulan}

Kabupaten Sumedang memiliki potensi alam dan sumber daya yang bernilai ekonomi dan produk kreatif. Selain itu latar belakang sejarah dan kearifan lokal menjadi daya tarik tersendiri bagi wisatawan baik lokal dan internasional untuk berkunjung ke daerah Sumedang.

Ikon wisata sejarah menjadi inspirasi produk cinderamata yang dapat menjadi oleh-oleh atau hadiah dan salah satu alternative pengembangan kesejahteraan dan revitalisasi budaya lokal masyarakat Sumedang.

\section{Ucapan Terima Kasih}

Terima kasih kepada RISTEKDIKTI melalui DIPA ISBI Bandung atas dukungan yang diberikan kepada tim peneliti berupa bantuan dana penelitian yang menunjang berlangsungnya penelitian Hibah Penciptaan Karya Seni Tahun 2018 ini.

\section{Kepustakaan}

Barrett-Graves, Debra, 2013. The Emblematic Queen : Extra-Literary Representation of Early Modern Queenship, New York: Palgrave Macmillan

BPS, 2017. Kabupaten Sumedang dalam Angka, Sumedang: Badan Pusat Statistik Kabupaten Sumedang.

Bramston, David, 2009. Material Thoughts: Basics Product Design, Switzerland : AVA Publishing SA

Danesi, Marcel. 2004, Pesan, Tanda, dan Makna, Yogyakarta: Jalasutra.

DEPDIKBUD, 1989, Kamus Besar Bahasa Indonesia, Jakarta, Balai Pustaka.

Dick, Stewart, 1912. Arts and Crafts OfOld Japan, Chicago: A.C. McLurg \& Co

Gruyter, De, 2003., Emblematics in Hungary: A study of the history of symbolic reprsentation in Renaissance and Baroque literature, Tubingen: Max Niemeyer Verlag

Hertati dkk, 2010. Ilmu Sosial dan Budaya Dasar. Jakarta: UT.

Karthadinata, Dewa Made, t.t. Studi tentang Pengembangan Desain Kerajinan Keramik Desa Mayong Lor Jepara, Semarang: Jurusan Seni Rupa Universitas Negeri Semarang

Keinonen, Turkka, Roope Takala (ed), 2006. Product Concept Design: A Review of The Conceptual Design of Products in Industry, Germany: Springer

Lasmiyati, 2014, "Ditioeng Memeh Hoedjan, Pemikiran Pangeran Aria Suria Atmadja dalam Memajukan Pemuda Pribumi di Sumedang (1800-1921)", Patanjala Vol. 6 No. 2 Juni 2014, 223-238

Reyes, Portia, 2008., Chairman Mao Badges: Symbols and Slogans of The Cultural Revolution, London: The British Museum Press

Mahroni, Lalu Aswandi, 2014. "Seni Kerajinan Gerabah Penunjak Lombok Tengah Nusa Tenggara Barat (Kontinuitas dan Perubahan)”, 
Jurnal Media Bina ilmiah Vol. 8 No. 3 Juli 2014, ISSN No. 1978-3787

Mujiyono, 2010, “Seni Rupa dalam Perspektif Metodologi Penciptaan: Refleksi atas Intuitif dan Metodis", Jurnal Seni Rupa Vol. VI No. 1 Januari 2010.

Sumardjo, Yakob, 2010, Estetika Paradoks, Bandung, Sunan Ambu STSI.

Supriatna, 2014, "Komunikasi Visual Seni Pertunjukan Kuda Renggong Kabupaten Sumedang”. Disertasi, Bandung, UNPAD.
Susanto, P.S Hary, 1987, Mitos, Yogyakarta, Kanisius.

Smith, T'ai, 2014. Bauhaus Weaving Theory: From Feminine craft to mode of design, London: University of Minnesota Press

Stemen, Sara E., 2013. Souvenir Nation, New York: Princeton Architectural Press

\section{Pustaka Laman}

http://www.sumedangkab.go.id 